\title{
Where is the common sense in aortic valve replacement? A review of hemodynamics and sizing of stented tissue valves
}

\author{
Torsten Doenst, MD, PhD, ${ }^{a}$ Paulo A. Amorim, MD, ${ }^{b}$ Nidal Al-Alam, MD, ${ }^{\mathrm{d}}$ Sven Lehmann, MD, \\ Chirojit Mukherjee, MD, ${ }^{c}$ and Gloria Faerber, $\mathrm{MD}^{\mathrm{a}}$
}

Heated debates revolve around the hemodynamic performance of stented aortic tissue valves. Because the opening area strongly influences the generation of a pressure gradient over the prosthesis, and the outer diameter determines which valve actually fits into the aortic root, it would seem logical that the valve with the greatest opening area in relation to its outer diameter should allow the best hemodynamic performance. Interestingly, neither of these 2 parameters is reflected by the manufacturing companies' size labels or suggested sizing strategies. In addition, it is known that valves with the same size label from different companies may differ significantly in their actual dimension (outer diameter). Finally, the manufacturer-suggested sizing strategies differ so much that expected differences from valve design may get lost because of differences in sizing. These size and sizing differences and the lack of information on the geometric opening area complicate true hemodynamic comparisons significantly. Furthermore, some fluid dynamic considerations regarding the determination of opening area by echocardiography (the effective orifice area) introduce additional obscuring factors in the attempt to compare hemodynamic performance data of different stented tissue valves. We analyzed the true dimensions of different tissue prostheses and the manufacturer-suggested sizing strategies in relation to published effective orifice areas. We have demonstrated how sizing and implantation strategy have much greater impact on postoperative valve hemodynamics than valve brand or type. In addition, our findings may explain the different opinions regarding valve hemodynamics of different tissue valves. (J Thorac Cardiovasc Surg 2011;142:1180-7)

The need to replace an aortic valve always raises the question of valve choice (mechanical or tissue), with a recent trend toward the preferred use of stented tissue valves in the great majority of cases. ${ }^{1}$ Tissue valves, however, have shorter long-term durability and also have smaller aortic valve opening area than do mechanical valves. ${ }^{2,3}$ These facts initiated a series of investigations comparing durability and hemodynamics of tissue valves. Interestingly, the hemodynamic comparisons have taken on an enormous perplexity because valve sizers, the valves themselves, and the manufacturers' size labeling and suggested sizing strategies are inconsistent. As a result, comparing hemodynamics among tissue valves today is similar to comparing apples to oranges.

As early as 1987, Bonchek and colleagues ${ }^{4}$ described a discrepancy between the true size and the nominal size of mechanical aortic valve sizers. This analysis was followed by several other descriptions of valve size and valve labeling inconsistencies, ${ }^{5-8}$ but daily practice is still challenged by

From the Department of Cardiothoracic Surgery, ${ }^{a}$ University of Jena, Jena, Germany; the Departments of Cardiac Surgery ${ }^{\mathrm{b}}$ and Anaesthesiology, ${ }^{\mathrm{c}}$ University of Leipzig Heart Center, Leipzig, Germany; and MediClin Heart Center, ${ }^{\mathrm{d}}$ Coswig, Germany.

T.D. is funded by the Deutsche Forschungsgemeinschaft (Do602/4-1, 6-1, 9-1) and has received honoraria for educational lectures on the topic from St Jude Medical GmbH, Eschborn, Germany.

Disclosures: Authors have nothing to disclose with regard to commercial support.

Received for publication Dec 21, 2010; revisions received April 13, 2011; accepted for publication May 5, 2011; available ahead of print June 27, 2011.

Address for reprints: Torsten Doenst, MD, PhD, Department of Cardiothoracic Surgery, Friedrich-Schiller-University of Jena, Erlanger Allee 101, 07747 Jena, Germany (E-mail: doenst@med.uni-jena.de).

$0022-5223 / \$ 36.00$

Copyright (c) 2011 by The American Association for Thoracic Surgery doi: $10.1016 /$ j.jtcvs.2011.05.007 a confusing myriad of valves with different dimensions, nominal sizes, and sizing strategies. In this analysis, we comprehensively review the true dimensions of tissue prostheses together with the manufacturer-suggested sizing strategies and relate them to their hemodynamic performance (effective orifice area [EOA] and pressure gradients). We conclude that sizing and implantation technique have a much greater impact on postoperative valve hemodynamics than valve brand or type. The rationale behind this conclusion requires a short review of some basics on valve sizes and sizing as well as of the echocardiographic determination of the aortic valve opening area, which are given in the following sections.

\section{PROSTHESIS WITH THE SAME SIZE LABEL DIFFER SIGNIFICANTLY IN THEIR OUTER DIAMETER}

Table 1 shows the outer diameters of the most commonly implanted tissue valve prostheses relative to their manufacturers' size labels and the diameters of their corresponding sizers. Figure 1 shows representative pictures of these valves together with their specific sizers. The values for the valves' outer diameters were obtained from the "small print" of the original packages of the valves. Companies are required to provide this information to obtain US Food and Drug Administration approval or Conformité Européene (CE) marking. The dimensions of the sizers were measured by us with a caliper.

The valve with the smallest outer diameter for a given size label is the Mitroflow (Sorin SpA, Milan, Italy) and the ones with the greatest outer diameters are the Perimount 


\section{Abbreviations and Acronyms}

$\mathrm{EOA}=$ effective orifice area

GOA $=$ geometric orifice area

LVOT $=$ left ventricular outflow tract

(Carpentier-Edwards Perimount model 2900; Edwards Lifesciences Corp, Irvine, Calif) for smaller sizes and the Mosaic (Mosaic aortic valve model 305; Medtronic, Inc, Minneapolis, Minn) for larger sizes. It is important to note that (1) none of the valves outer dimension corresponds to the size label and (2) there is great variability among the different manufacturers. One reason for the mismatch of outer diameter to size label and the great variability may be the fact that the label is derived from the inner diameters of the valves' stents. The variability would then originate from differences in sewing ring and stent designs. Christakis and associates, ${ }^{8}$ however, demonstrated before that even the inner diameters differ significantly and do not always match the size label. Irrespective of the labeling, the outer diameter is key for implantation of the valve into the aortic root. From a commonsense perspective, the outer diameter should determine the maximal size of a valve that can be implanted. Inspecting Table 1 would then suggest that if a size 21 Perimount can be implanted, a size $23 \mathrm{Ma}-$ gna (Magna, Carpentier-Edwards Perimount Magna model 3000; Edwards Lifesciences), size 25 Mitroflow, or size 25 Epic (Epic Aortic; St Jude Medical, Inc, St Paul, Minn) should also fit (their outer diameters are all 28 or $29 \mathrm{~mm}$ ). This reasoning is intriguing and will be addressed in more detail.

\section{VALVE-SPECIFIC SIZERS ARE NOT ALWAYS METRIC AND DIFFER AMONG MANUFACTURERS}

The sizer dimensions are also not uniform. Whereas the Perimount and Epic sizers are metric and reflect the size label, the true diameters of the other sizers differ significantly from their labels. In case of the Epic Supra (St Jude Medical) and the Magna, this deviation is understandable, because the sizer is a valve replica and the sizing strategy is based in the position of the valve in the aortic root, and the base model sizer is only used to get a "first size impression." For the Mosaic and the Mitroflow, the suggested sizing strategies are comparable to those of the Perimount or the Epic (based on sizing the dimension of the left ventricular outflow tract [LVOT]); however, the dimensions of the sizers are either 2 to $3 \mathrm{~mm}$ greater (Mitroflow) or smaller (Mosaic) than their labels. The result is the selection of valves with different size labels for the same patient when using the Perimount or Epic on the one hand or the Mitroflow or Mosaic on the other (Figure 2,C). Inspecting
Table 1 would then suggest that if a 23 Perimount sizer reflects the appropriate size, a 25 Mosaic sizer and a 21 Mitroflow sizer should fit the same. Thus for the same patient a size 23 Perimount, a size 25 Mosaic, or a size 21 Mitroflow would be selected according to the manufacturersuggested sizing strategy.

To summarize the information in Table 1, valve size selection is misleading because the sizers differ in their dimensions, and comparisons of hemodynamic performance is confusing because valves with different size labels would be selected for the same patient. In addition, the valves differ in their outer dimensions (their true size; Table 1). Thus hemodynamic comparisons according to manufacturer size label are inappropriate and inadvertently lead to erroneous conclusions.

Figure 2 illustrates this confusion by comparing the sizer dimensions to the valves' outer diameters and the mean EOAs published for each size in the literature. The source references are listed in the figure legend, and Table 2 lists all the studies used for this analysis along with their values. The relationship of mean EOAs to the size labels (Figure 2, A) gives a completely different impression of the individual valve area than does the relationships of EOAs to the outer diameter (Figure 2, B). The impression is again changed if one compares the EOAs determined for the different valves as they would be selected by the manufacturer-suggested sizing strategies (Figure 2, C). The comparison in Figure 2, $C$, probably reflects "real life" most accurately. Inspecting this figure more closely reveals that the hemodynamic performance (as judged by the EOA) is similar for most of the different manufacturers. Two valves, however, appear to perform worse (the Epic and the Mitroflow). We illustrate further here that this clinically relevant poor performance of these valves is, however, not due to valve design.

\section{IMPLANTATION TECHNIQUE AND SIZING STRATEGIES SIGNIFICANTLY AFFECT PRESSURE GRADIENTS AND AORTIC VALVE AREAS AS MEASURED BY ECHOCARDIOGRAPHY}

Echocardiography is the main diagnostic tool for the assessment of preoperative and postoperative pressure gradients and aortic valve area. The aortic valve area is mostly obtained from the continuity equation and relies on the assessment of flow velocity over the prosthesis and the dimension of the LVOT. The greater the difference between the dimension of the LVOT and the aortic valve area, the more the bloodstream will be compressed when passing through the opening. The site of maximal compression of the bloodstream is termed the vena contracta. The continuity equation states that the product of the flow velocity and the area of the LVOT equals the same product at the vena contracta. Thus flow velocity increases as the bloodstream 
TABLE 1. External diameters of the most commonly implanted aortic tissue prostheses and their corresponding sizers, as shown in Figure 1

\begin{tabular}{llllclc}
\hline & \multicolumn{5}{c}{ External diameter $(\mathbf{m m})$} \\
\cline { 2 - 7 } Size label & Epic & Supra & Mosaic & Perimount & Magna & Mitroflow \\
\hline Valves & & & & & & \\
19 & - & 25 & 25 & 26 & 24 & 21 \\
21 & 25 & 27 & 27 & 29 & 26 & 24 \\
23 & 27 & 29 & 30 & 31 & 28 & 26 \\
25 & 29 & 31 & 33 & 33 & 30 & 28 \\
27 & 31 & 33 & 36 & 35 & 32 & 32 \\
Sizers & & & & & & \\
19 & - & 25 & 17 & 19 & 23 & 21 \\
21 & 21 & 27 & 18.5 & 21 & 25 & 23 \\
23 & 23 & 29 & 20.5 & 23 & 27 & 26 \\
25 & 25 & 31 & 22.5 & 25 & 28.7 & 28 \\
27 & 27 & 33 & 24 & 27 & 31 & 31 \\
\hline
\end{tabular}

Epic, Epic Aortic St Jude Medical, Inc, St Paul, Minn; Supra, Epic Supra; St Jude Medical; Mosaic, Mosaic aortic valve model 305; Medtronic, Inc, Minneapolis, Minn; Perimount, Carpentier-Edwards Perimount model 2900; Edwards Lifesciences, Corp, Irvine, Calif; Magna, Carpentier-Edwards Perimount Magna model 3000; Edwards Lifesciences; Mitroflow, Mitroflow; Sorin SpA, Milan, Italy.

is compressed. The EOA is the cross-sectional area of the compressed bloodstream at the level of the vena contracta (see Garcia and Kadem ${ }^{9}$ for a detailed review).

Although the EOA reflects a functionally relevant parameter for the patient, it is often taken as measure of the aortic valve area. ${ }^{10-12}$ This assumption is inappropriate, because it may lead to the conclusion that EOA is identical to the geometric orifice area (GOA). As Figure 3 schematically illustrates, however, the EOA may (ideally) but does not necessarily have to equal the GOA. The importance of this difference becomes clear with the following example. Consider $\mathrm{A}$ and $\mathrm{B}, 2$ different patients with 2 different anatomies ( 1 with wide LVOT and aorta, Figure 3, A, and the other with slim LVOT and aorta, Figure 3, B). Implantation of the identical valve into these 2 patients (which can be achieved by different positioning and sizing) results in different EOAs as assessed by echocardiography, although the GOAs are identical. Thus taking EOA as a measure of valve area is incorrect. The GOA should be referred to for intervalve comparisons. It is practically impossible, however, to find published assessments of the true GOAs of the valves (most values are inappropriately based on calculating the inner stent area assuming that the valves open completely $^{13-15}$ rather than on planimetric measurements of the open orifice). Yet the GOA is critical to assess the hemodynamic properties of a valve because it can be related to the outer diameter of the valve or stent. This relationship would make different valves directly comparable with respect to their hemodynamic potential independent of implantation technique, whereas assessing EOA provides information on functional relevance of an implanted valve in an individual patient. It is possible, however, that because of different construction methods different valves may not open fully under given flow conditions and that GOAs may vary for the same valve depending on flow and pressure conditions. From our perspective, a range of GOAs could then be given for such a valve, because the principal importance of this value for hemodynamic performance of the prosthesis and the generation of the individual EOA remains the same.

These considerations suggest that (1) trying to compare prosthetic valve areas on the basis of EOA determination is inappropriate, and (2) surgical technique, including sizing, may have a greater influence on postoperative hemodynamics than the selection of a specific valve type. Indeed, the literature provides convincing evidence for this conclusion. Figure 4 shows the average published EOAs for the

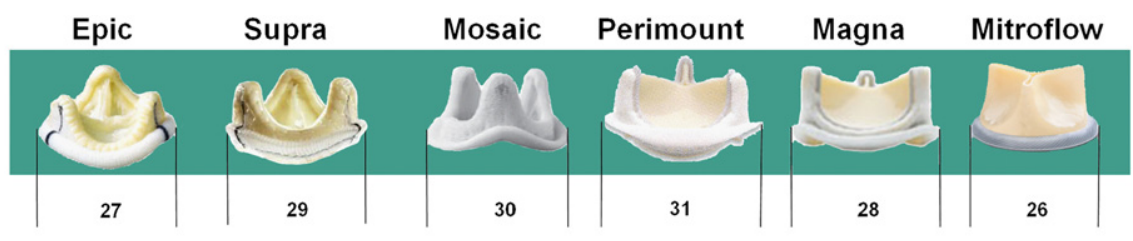

A

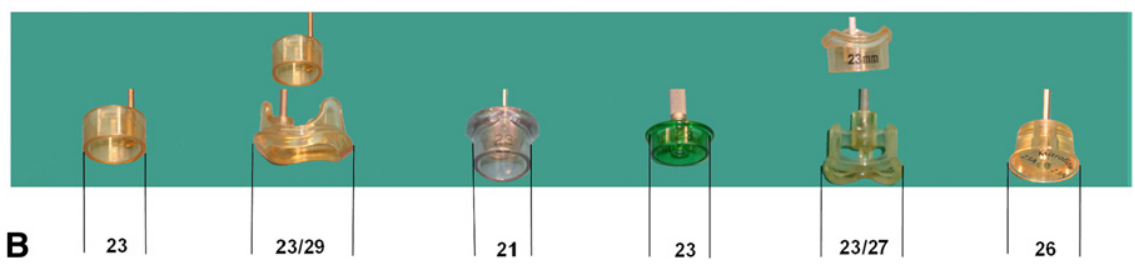

FIGURE 1. Representative photographs of 6 stented tissue valves used for the analyses in this article (A) and their corresponding sizers (B). Selection of a valve size is based on fitting the sizer in the left ventricular outflow tract. In the cases of Supra and Magna, a valve replica is used to assess placement of the valve in the aortic root after the base sizer has been used. Epic, Epic Aortic St Jude Medical, Inc, St Paul, Minn; Supra, Epic Supra; St Jude Medical; Mosaic, Mosaic aortic valve model 305; Medtronic, Inc, Minneapolis, Minn; Perimount, Carpentier-Edwards Perimount model 2900; Edwards Lifesciences Corp, Irvine, Calif; Magna, Carpentier-Edwards Perimount Magna model 3000; Edwards Lifesciences; Mitroflow, Mitroflow; Sorin SpA, Milan, Italy. 
Comparisons based on manufacturers' size label

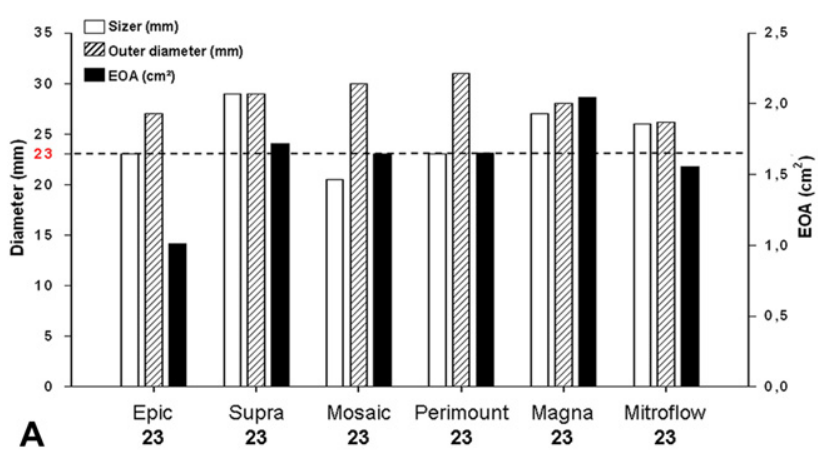

Comparisons based on outer diameter

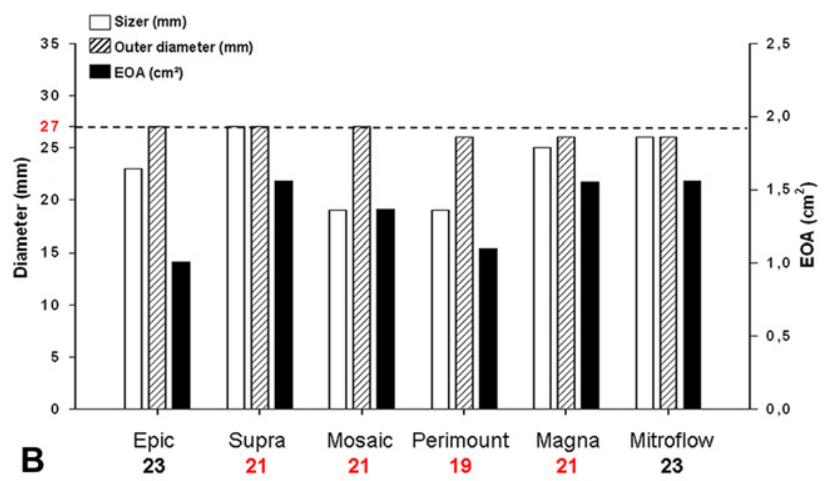

Comparisons based on sizing strategies

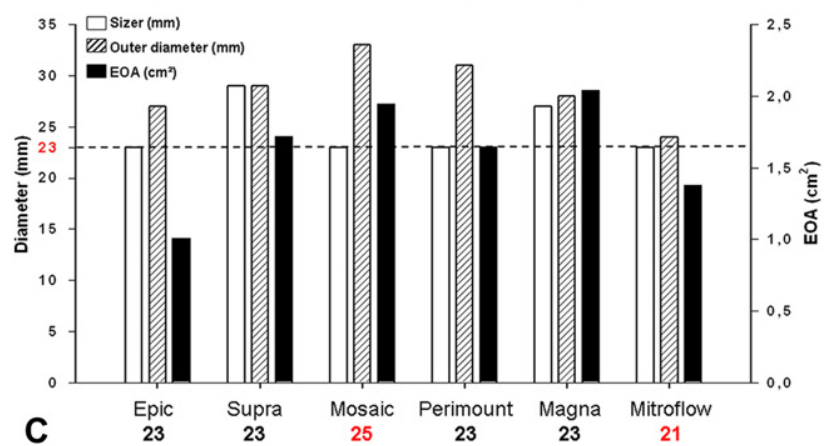

FIGURE 2. Comparison of sizer dimension (open bars), outer diameter (hatched bars), and average published effective orifice area (EOA, filled bars) values among 6 commonly implanted stented aortic tissue valves shown in Figure 1. A, Comparisons based on manufacturers' size labels. $\mathrm{B}$, Comparisons based on outer diameters. C, Comparisons based on sizing strategy as suggested by the manufacturer with the sizers shown in Figure 1. Sizers are for sizing the outflow tract dimension (Epic, Mosaic, Perimount, Mitroflow) or for the supra-annular position of the valve (Supra, Magna). Values for effective orifice area were calculated as the mean value of published data from the following references: Epic, ${ }^{17}$ Supra, ${ }^{18}$ Mosaic, ${ }^{19-21}$ Perimount, ${ }^{17,19,20,22-30}$ Magna, ${ }^{16,31,32}$ and Mitroflow. ${ }^{33-35}$ The original values are listed in Table 2, and manufacturer values are not included.

Epic and the Epic Supra valves, as well as the Perimount and the Magna valves (Table 2 and Figure 4 give source references). We used sizes 21 and 23 for this illustration, because these are the most frequently implanted valve sizes. ${ }^{16}$ Both St Jude Medical and Edwards Lifesciences have modified the sewing rings of their base models (Epic and Perimount, respectively) without actually altering the valve and the stent on which it is mounted. Thus the actual valve apparatus of the size 23 Epic is identical to that of the size 21 Epic Supra. Because of the different sizing strategy (the use of a replica is recommended), a larger stent (and thereby valve) can be implanted in the same patient. In the case of the Perimount and Magna prostheses, the sewing ring was tapered so that the Magna is still labeled the same, but the outer diameter is roughly $3 \mathrm{~mm}$ slimmer for a given size (Table 1). Because the Magna also comes with a replica, a size 23 Magna can often be implanted in a root that would fit a size 21 Perimount. Similar modifications were done on the Mosaic to generate the Mosaic Ultra (Medtronic), with a slimmer outer diameter; however, the published EOAs are not size specific for the Mosaic Ultra and are therefore not illustrated.

The comparisons in Figure 4 illustrate with "real life" data the fluid dynamic relevance of these modifications for echocardiographic EOA determination. In both cases, the new (next generation) valve results in the determination of greater echocardiographic EOAs. In other words, although the valve apparatuses of both the two St Jude Medical valves and the two Edwards valves are geometrically identical (specifically in GOA), the EOAs as determined by echocardiography are substantially greater in the "next generation" valves (Epic Supra and Magna, respectively). These results support the conclusion that the difference in assessed opening area is due to the described fluid dynamic effect, which in turn is based on the implantation of the greater valve relative to the LVOT in the next generation valves relative to the base model. Therefore differences in valve stent or leaflet design seem to be less important.

\section{DIFFERENCES IN FLUID DYNAMIC EFFECTS AND SIZING STRATEGIES EXPLAIN DIFFERENCES IN OPINION ON TISSUE VALVE HEMODYNAMICS}

The illustrated fluid dynamic effects, together with differences in the "aggressiveness" of manufacturersuggested sizing strategies, may also explain the different opinions on individual valve hemodynamics. Inspection of Table 1 reveals that the outer diameter of the size 21 Epic is $2 \mathrm{~mm}$ smaller than that of the size 21 Mosaic. The differences in sizing strategies, however, result in the implantation of even a size 23 Mosaic valve (outer diameter $30 \mathrm{~mm}$ ) in a patient for whom a size 21 Epic (outer diameter $25 \mathrm{~mm}$ ) would be chosen (both sizers are 21 $\mathrm{mm})$. The same effect can be found when comparing Epic and Perimount. In that case, the sizers are identical but the outer diameter of the Perimount $(29 \mathrm{~mm})$ is significantly larger than that of the Epic $(25 \mathrm{~mm})$, resulting in the implantation of the bigger valve when selecting the 
TABLE 2. Reference sources for published effective orifice areas and calculations of mean effective orifice area used for comparisons of valves shown in Figure 1

\begin{tabular}{|c|c|c|c|c|c|}
\hline \multirow[b]{2}{*}{ Effective orifice area $\left(\mathrm{cm}^{2}\right)$} & \multicolumn{5}{|c|}{ Manufacturer labeled valve size } \\
\hline & 19 & 21 & 23 & 25 & 27 \\
\hline \multicolumn{6}{|l|}{ Epic } \\
\hline Goetzenich et $\mathrm{al}^{17}$ & - & 0.8 & 1.0 & 1.2 & 2.2 \\
\hline \multicolumn{6}{|l|}{ Supra } \\
\hline Sakwa et al ${ }^{18}$ & 1.5 & 1.6 & 1.7 & - & - \\
\hline \multicolumn{6}{|l|}{ Mosaic } \\
\hline Eichinger et al ${ }^{19}$ & 0.8 & 1.4 & 1.6 & 2.4 & 2.2 \\
\hline Seitelberger et $\mathrm{al}^{20}$ & - & 1.3 & 1.6 & 1.7 & 2.2 \\
\hline Dalmau et $\mathrm{al}^{21}$ & 1.3 & 1.4 & 1.7 & 1.8 & 2.1 \\
\hline Mean \pm SD & $1.4 \pm 0.4$ & $1.4 \pm 0.1$ & $1.6 \pm 0.0$ & $1.9 \pm 0.4$ & $2.1 \pm 0.1$ \\
\hline \multicolumn{6}{|l|}{ Perimount } \\
\hline Eichinger et al ${ }^{19}$ & 1.0 & 1.4 & 1.9 & 2.1 & 2.1 \\
\hline Maslow et $\mathrm{al}^{23}$ & 1.0 & 1.4 & 1.9 & 2.6 & 3.1 \\
\hline Botzenhardt et $\mathrm{al}^{24}$ & 1.0 & 1.4 & 1.9 & 2.1 & - \\
\hline McDonald et $\mathrm{al}^{25}$ & 1.2 & 1.5 & 1.8 & - & - \\
\hline Aupart et $\mathrm{al}^{26}$ & 1.1 & 1.3 & 1.4 & 1.5 & 2.2 \\
\hline Aupart et $\mathrm{al}^{27}$ & 1.1 & 1.4 & 1.7 & 1.9 & - \\
\hline Seitelberger et $\mathrm{al}^{20}$ & 1.3 & 1.4 & 1.7 & 1.8 & 2.2 \\
\hline Rao et $\mathrm{al}^{22}$ & 1.3 & 1.5 & 1.8 & 2.0 & 2.1 \\
\hline Goetzenich et al $^{17}$ & - & 1.2 & 1.4 & 1.6 & 1.4 \\
\hline Banbury et $\mathrm{al}^{28}$ & 0.8 & 1.0 & 1.2 & 1.1 & - \\
\hline 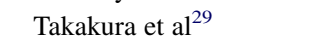 & 1.6 & - & - & - & - \\
\hline Dellgren et $\mathrm{al}^{30}$ & 1.0 & 1.1 & 1.5 & 1.4 & 1.6 \\
\hline Mean \pm SD & $1.1 \pm 0.2$ & $1.3 \pm 0.2$ & $1.6 \pm 0.2$ & $1.8 \pm 0.4$ & $2.1 \pm 0.5$ \\
\hline \multicolumn{6}{|l|}{ Magna } \\
\hline Borger et al ${ }^{31}$ & 1.2 & 1.3 & 1.4 & 1.4 & 1.6 \\
\hline Dalmau et $\mathrm{al}^{16}$ & 1.4 & 1.8 & 2.2 & 2.4 & 2.0 \\
\hline Botzenhardt et $\mathrm{al}^{32}$ & 1.7 & 1.7 & 2.5 & 2.3 & - \\
\hline Mean \pm SD & $1.4 \pm 0.3$ & $1.6 \pm 0.3$ & $2.0 \pm 0.6$ & $2.0 \pm 0.5$ & $1.8 \pm 0.3$ \\
\hline \multicolumn{6}{|l|}{ Mitroflow } \\
\hline Tasca et al ${ }^{33}$ & 1.2 & 1.4 & 1.6 & - & - \\
\hline Bleiziffer et $\mathrm{al}^{34}$ & 1.0 & 1.4 & 1.6 & 2.0 & 2.4 \\
\hline García-Bengochea et $\mathrm{al}^{35}$ & 1.1 & 1.3 & 1.5 & 1.8 & - \\
\hline Mean \pm SD & $1.1 \pm 0.1$ & $1.4 \pm 0.1$ & $1.6 \pm 0.1$ & $1.9 \pm 0.2$ & - \\
\hline
\end{tabular}

Epic, Epic Aortic St Jude Medical, Inc, St Paul, Minn; Supra, Epic Supra; St Jude Medical; Mosaic, Mosaic aortic valve model 305; Medtronic, Inc, Minneapolis, Minn; Perimount, Carpentier-Edwards Perimount model 2900; Edwards Lifesciences Corp, Irvine, Calif; Magna, Carpentier-Edwards Perimount Magna model 3000; Edwards Lifesciences; Mitroflow, Mitroflow; Sorin SpA, Milan, Italy.

Perimount. Thus the impression may arise that the Epic may be hemodynamically inferior. It is not the valve, however, but the sizing strategy and implantation technique that cause the implantation of prostheses with different actual dimensions and therefore allow us to arrive at this conclusion. Thus the question whether these valves actually display true differences in hemodynamic properties cannot be answered at this time.

An example for an erroneous assumption of the hemodynamic superiority of a specific tissue valve can be found for instance by comparing the Mitroflow with the Mosaic. The Mitroflow has been designed for improved hemodynamic performance. The pericardial cusps of the valve are wrapped around the stent and therefore provide more valve opening in relation to the outer diameter of the prosthesis than do other valves. The majority of this hemodynamic advantage by design, however, is lost by a "defensive" sizing strategy. An aortic root that is sized to host a size 19 Mitroflow will result in the selection of a size 23 Mosaic according to the Medtronic sizing strategy (both sizers have a diameter of $21 \mathrm{~mm}$ ). The size 23 Mosaic, however, has an outer diameter that is $9 \mathrm{~mm}$ larger than that of the Mitroflow (Table 1). Thus the design advantage of the Mitroflow is overcome by the Mosaic (according to manufacturer size comparisons) through the placement of a larger valve selected by a different sizing strategy. It is very likely that the actual GOA of the size 23 Mosaic is the same as or even bigger than that of the size 19 Mitroflow. Again, actual values for GOA are not available, but the average EOAs found in the literature for these prostheses indirectly support our conclusion 

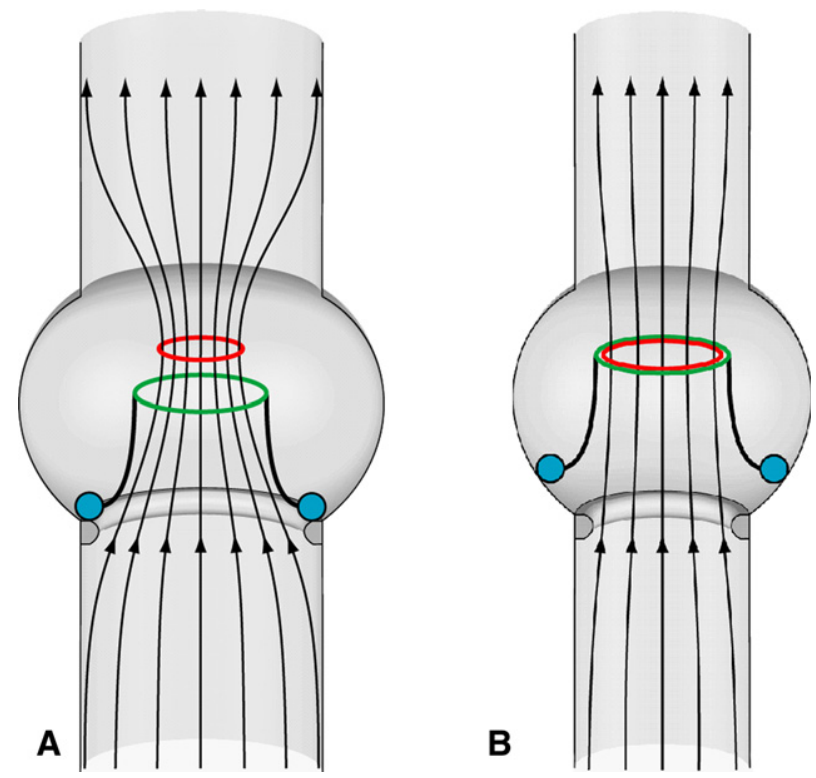

FIGURE 3. Idealized illustration of the influence of valve position and relationship between geometric orifice area ( green) and left ventricular outflow tract on the determination of the effective orifice area (red) by echocardiography. A, If a tissue valve leaves a rest stenosis after replacement, the size of maximal bloodstream contraction (vena contracta) moves distally to the geometric valve opening. As a consequence, effective orifice area underestimates geometric orifice area. B, Ideal hemodynamic placement of the same tissue valve would place the vena contracta at the site of the geometric orifice area of the tissue valve, and effective orifice area would then equal geometric orifice area.

(Figure 2, C). Here the Mosaic is even seen to have a greater EOA than the Mitroflow.

\section{SUPRA-ANNULAR AND INTRA-ANNULAR PLACEMENT OF A PROSTHESIS IS DETERMINED BY THE SURGEON AND NOT BY STENT DESIGN}

The conclusion that sizing and implant strategy significantly affects the hemodynamic performance of a tissue valve prosthesis requires addressing surgical technique. The bulging shape of the aortic root allows the implantation of a tissue valve into the root above the actual annulus. This supra-annular placement requires sutures to be placed from underneath the aortic annulus to the aortic root above the annulus (Figure $5, A$ ). If the stitching direction is reversed, and the sutures exit the tissue inside the LVOT, the valve receives an intra-annular position (Figure $5, B$ ). Industry has taken this terminology to design specific valves for supra-, intra-, or even supraintra-annular placement. It is important to realize, however, that the exit point of the sutures below, above, or even in the aortic annulus determines the final position of the prostheses, a condition that is relatively independent of stent design (Figure 5, $A$ and $B$ ). It is also important to realize that the supra-annular placement of a tissue prosthesis does not automatically result in superior
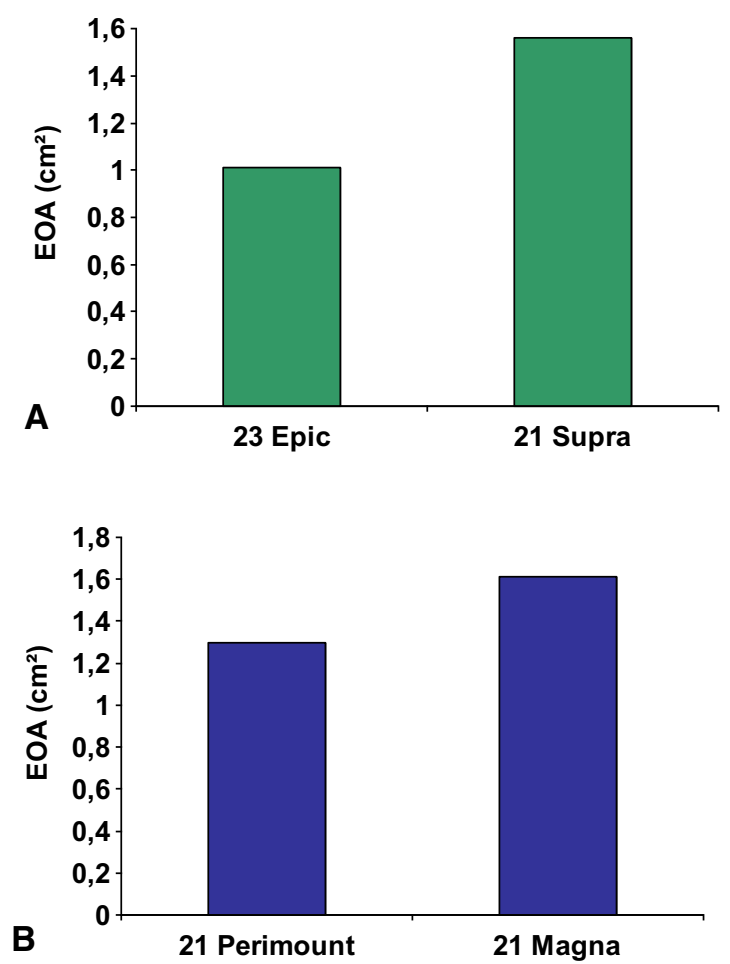

FIGURE 4. Comparisons of published effective orifice area (EOA) values from the size 23 Epic and the size 21 Epic Supra prostheses (A) and the Perimount and Perimount Magna prostheses (B). Note that in both A and B the 2 prostheses compared have geometrically identical stent design and differ only in the sewing ring (see Figure 1 for valve designs and Table 2 for the source references).

hemodynamics. Figure 5 also illustrates this statement. Inarguably, an intra-annular placement of a tissue valve always results in loss of possible valve opening by placing the sewing ring inside the LVOT (Figure 5,C). Supraannular placement allows placement of the inner margin of the stent (the prosthetic valve itself) over the annulus by "hiding" the sewing ring in the aortic root (Figure 3 and Figure 5, A). If a defensive sizing strategy is selected or a smaller valve size is selected by the surgeon for one reason or another, however, hemodynamics may be poor despite supra-annular placement of the prosthesis because the LVOT may become tapered down (Figure 5, D).

\section{WHAT SHOULD BE CHANGED FOR EVERYDAY PRACTICE OF STENTED TISSUE VALVE REPLACEMENT?}

There are several objectives that need to be met by those who are involved in the treatment and care of patients requiring aortic tissue valve replacement. The first step is the recognition of these phenomena and full comprehension of the topic to be able to put echocardiographically determined values for EOA and pressure gradients into perspective. These data are relevant for the patient but cannot be 

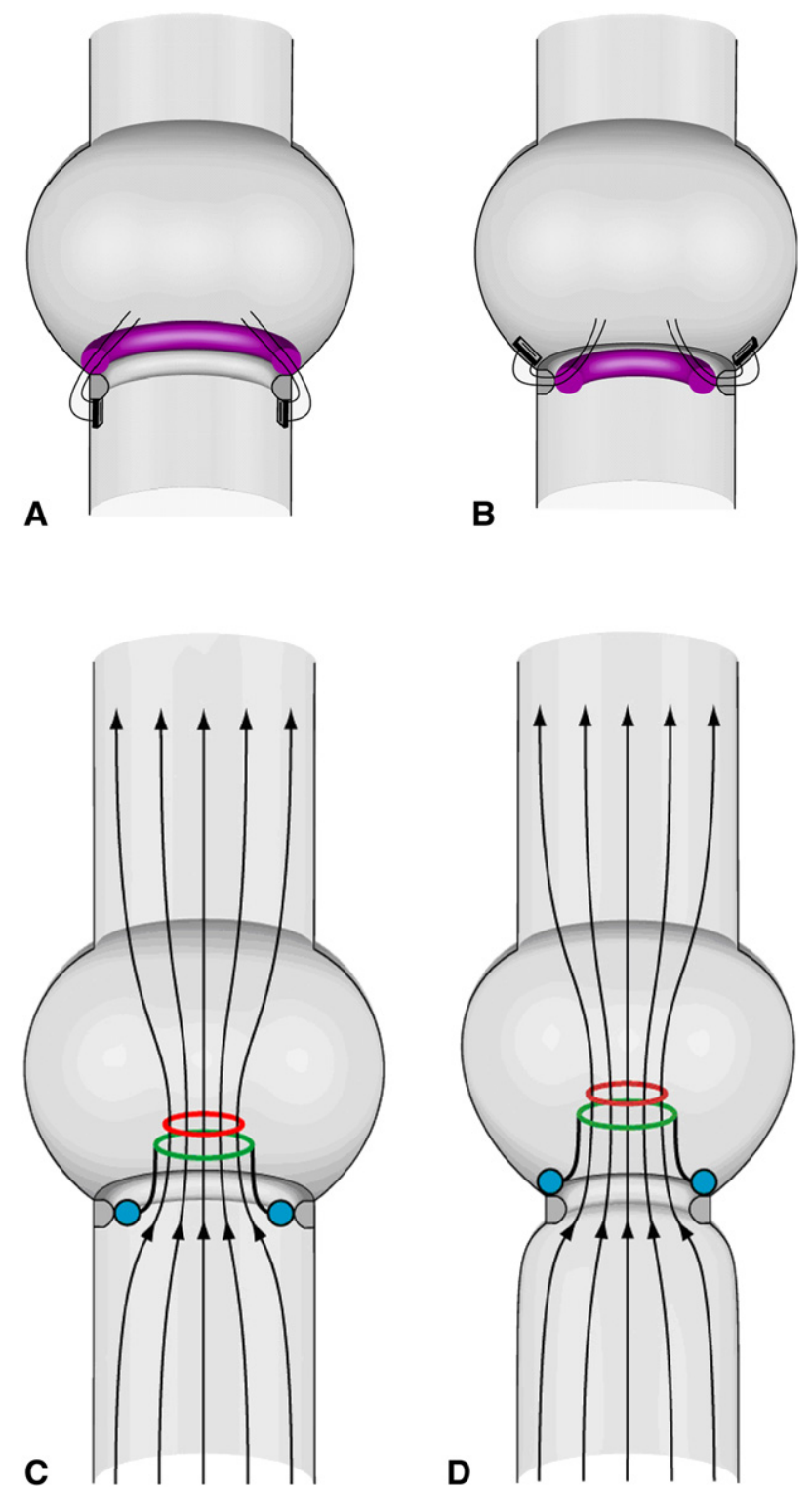

FIGURE 5. Schematic demonstration of supra-annular (A) and intraannular (B) placements of a valve prosthesis (violet) based on stitching direction as well as illustration of intra-annular (C) or supra-annular (D) placement of the same size tissue valve. Note that supra-annular placement does not confer the expected hemodynamic benefit if the chosen valve is too small, because it will result in tapering of the aortic annulus (eg, with a defensive sizing strategy). Red ring, Effective orifice area; green ring, geometric orifice area.

used to compare hemodynamic properties of different stented tissue valves. For that, parameters independent of individual anatomy are required (such as the GOA and the outer diameter of the prosthesis). Second, industry would help the surgeon to implant the biggest size possible by providing true valve replicas for optimal sizing (as is beginning to be the case with the newer generation tissue valves, the Epic Supra, the Perimount Magna Ease [Edwards
Lifesciences], the Mosaic Ultra, and the brand new Trifecta [St Jude Medical]). Third, surgeons should continue to improve the ability to implant large prostheses by assessing aortic root geometry, applying valve replicas, and respecting geometric differences between patient and prosthesis commissures when implanting the valve. Finally, presenting the GOAs of the individual prostheses would allow surgeons, cardiologists, and anesthesiologists to compare the determined EOA with the GOA. This information would give an impression about the hemodynamic quality of valve placement. The closer the EOA is to the GOA, the hemodynamically better the valve is positioned in the root. This simple comparison might be an extremely valuable tool to determine the hemodynamic relevance of an aortic valve prosthesis and its relation to the way it is implanted. Issues such as angulation of the prosthesis in the aortic root, as well as the angle between the LVOT axis and the axis of the ascending aorta, affect fluid dynamics and energy loss (not specifically addressed in this article). All these influences would be considered by comparing the individual EOA of the patient with the GOA of the prosthesis.

\section{CONCLUSIONS}

Here we present evidence emphasizing how lack of uniformity in tissue valve size and sizer specifications makes proper hemodynamic comparisons among different tissue valves difficult and misleading. We highlight the concept that a geometric implantation technique together with replica-based valve sizing might yield optimal hemodynamic outcome which may be easily assessed by relating EOA and GOA. Finally, we conclude that for the currently available stented tissue valves, surgical implantation technique and the current sizing strategies are together greater determinants of postoperative hemodynamic performance than valve type, brand, or design.

We thank Tirone David, MD, for many helpful discussions, valuable advice, and inspiration for finding the right article title.

\section{References}

1. Puvimanasinghe JP, Takkenberg JJ, Eijkemans MJ, Steyerberg EW, van Herwerden LA, Grunkemeier GL, et al. Choice of a mechanical valve or a bioprosthesis for AVR: does CABG matter? Eur J Cardiothorac Surg. 2003;23: 688-95.

2. Rahimtoola SH. Choice of prosthetic heart valve for adult patients. J Am Coll Cardiol. 2003;41:893-904.

3. Reagan BW, Kerut EK. Patient-prosthetic aortic valve mismatch: role of the echocardiographer. Echocardiography. 2005;22:365-6.

4. Bonchek LI, Burlingame MW, Vazales BE. Accuracy of sizers for aortic valve prostheses. J Thorac Cardiovasc Surg. 1987;94:632-4.

5. Sievers HH. Prosthetic aortic valve replacement. J Thorac Cardiovasc Surg. 2005; 129:961-5.

6. Walther T, Falk V, Weigl C, Diegeler A, Rauch T, Autschbach R, et al. Discrepancy of sizers for conventional and stentless aortic valve implants. J Heart Valve Dis. 1997;6:145-8.

7. Cochran RP, Kunzelman KS. Discrepancies between labeled and actual dimensions of prosthetic valves and sizers. J Card Surg. 1996;11:318-25. 
8. Christakis GT, Buth KJ, Goldman BS, Fremes SE, Rao V, Cohen G, et al. Inaccurate and misleading valve sizing: a proposed standard for valve size nomenclature. Ann Thorac Surg. 1998;66:1198-203.

9. Garcia D, Kadem L. What do you mean by aortic valve area: geometric orifice area, effective orifice area, or Gorlin area? J Heart Valve Dis. 2006;15:601-8.

10. Levine RA, Schwammenthal E. Stenosis is in the eye of the observer: impact of pressure recovery on assessing aortic valve area. J Am Coll Cardiol. 2003;41: 443-5.

11. Garcia D, Pibarot P, Landry C, Allard A, Chayer B, Dumesnil JG, et al. Estimation of aortic valve effective orifice area by Doppler echocardiography: effects of valve inflow shape and flow rate. J Am Soc Echocardiogr. 2004;17: 756-65.

12. Pibarot P, Dumesnil JG. Prosthetic heart valves: selection of the optimal prosthesis and long-term management. Circulation. 2009;119:1034-48.

13. Bridges CR, O'Brien SM, Cleveland JC, Savage EB, Gammie JS, Edwards FH, et al. Association between indices of prosthesis internal orifice size and operative mortality after isolated aortic valve replacement. J Thorac Cardiovasc Surg. 2007;133:1012-21.

14. Hashimoto K. Patient-prosthesis mismatch: the Japanese experience. Ann Thorac Cardiovasc Surg. 2006;12:159-65.

15. Blackstone EH, Cosgrove DM, Jamieson WR, Birkmeyer NJ, Lemmer JH Jr, Miller DC, et al. Prosthesis size and long-term survival after aortic valve replacement. J Thorac Cardiovasc Surg. 2003;126:783-96.

16. Dalmau MJ, Mariagonzález-Santos J, López-Rodriguez J, Bueno M, Arribas A. The Carpentier-Edwards Perimount Magna aortic xenograft: a new design with an improved hemodynamic performance. Interact Cardiovasc Thorac Surg. 2006;5:263-7.

17. Goetzenich A, Langebartels G, Christiansen S, Hatam N, Autschbach R, Dohmen G. Comparison of the Carpentier-Edwards Perimount and St. Jude Medical Epic bioprostheses for aortic valve replacement-a retrospective echocardiographic short-term study. J Card Surg. 2009;24:260-4.

18. Sakwa MP, Shannon FL, Altshuler JM, Tepe NA, Hanson EA, Mitchell D, et al. Hemodynamic performance of the St. Jude Medical Biocor Supra Aortic Valve in the small aortic root. In: Proceedings of the 4th Biennial Meeting of The Society for Heart Valve Disease; 2007Jun 15-18; New York NY. P141.

19. Eichinger WB, Botzenhardt F, Guenzinger R, Bleiziffer S, Keithahn A, Bauernschmitt $\mathrm{R}$, et al. The effective orifice area/patient aortic annulus area ratio: a better way to compare different bioprostheses? A prospective randomized comparison of the Mosaic and Perimount bioprostheses in the aortic position. J Heart Valve Dis. 2004;13:382-9.

20. Seitelberger R, Bialy J, Gottardi R, Seebacher G, Moidl R, Mittelböck M, et al. Relation between size of prosthesis and valve gradient: comparison of two aortic bioprosthesis. Eur J Cardiothorac Surg. 2004;25:358-63.

21. Dalmau MJ, Maria González-Santos J, López-Rodriguez J, Bueno M, Arribas A, Nieto F. One year hemodynamic performance of the Perimount Magna pericardial xenograft and the Medtronic Mosaic bioprosthesis in the aortic position: a prospective randomized study. Interact Cardiovasc Thorac Surg. 2007;6:345-9.
22. Rao V, Jamieson WR, Ivanov J, Armstrong S, David TE. Prosthesis-patient mismatch affects survival after aortic valve replacement. Circulation. 2000;102(19 Suppl 3):III5-9.

23. Maslow AD, Haering JM, Heindel S, Mashikian J, Levine R, Douglas P. An evaluation of prosthetic aortic valves using transesophageal echocardiography: the double-envelope technique. Anesth Analg. 2000;91:509-16.

24. Botzenhardt F, Eichinger WB, Bleiziffer S, Guenzinger R, Wagner IM, Bauernschmitt R, et al. Hemodynamic comparison of bioprostheses for complete supra-annular position in patients with small aortic annulus. J Am Coll Cardiol. 2005;45:2054-60.

25. McDonald ML, Daly RC, Schaff HV, Mullany CJ, Miller FA, Morris JJ, et al. Hemodynamic performance of small aortic valve bioprostheses: is there a difference? Ann Thorac Surg. 1997;63:362-6.

26. Aupart MR, Sirinelli AL, Diemont FF, Meurisse YA, Dreyfus XB Marchand MA. The last generation of pericardial valves in the aortic position: ten-year follow-up in 589 patients. Ann Thorac Surg. 1996;61:615-20.

27. Aupart MR, Mirza A, Meurisse YA, Sirinelli AL, Neville PH, Marchand MA Perimount pericardial bioprosthesis for aortic calcified stenosis: 18-year experience with 1133 patients. J Heart Valve Dis. 2006;15:768-76.

28. Banbury MK, Cosgrove DM 3rd, Thomas JD, Blackstone EH, Rajeswaran J, Okies JE, et al. Hemodynamic stability during 17 years of the CarpentierEdwards aortic pericardial bioprosthesis. Ann Thorac Surg. 2002;73:1460-5.

29. Takakura H, Sasaki T, Hashimoto K, Hachiya T, Onoguchi K, Oshiumi M, et al Hemodynamic evaluation of 19-mm Carpentier-Edwards pericardial bioprosthesis in aortic position. Ann Thorac Surg. 2001;71:609-13.

30. Dellgren G, David TE, Raanani E, Armstrong S, Ivanov J, Rakowski H. Late hemodynamic and clinical outcomes of aortic valve replacement with the Carpentier-Edwards Perimount pericardial bioprosthesis. J Thorac Cardiovasc Surg. 2002;124:146-54.

31. Borger MA, Nette AF, Maganti M, Feindel CM. Carpentier-Edwards Perimoun Magna valve versus Medtronic Hancock II: a matched hemodynamic comparison. Ann Thorac Surg. 2007;83:2054-8.

32. Botzenhardt F, Eichinger WB, Guenzinger R, Bleiziffer S, Wagner I, Bauernschmitt R, et al. Hemodynamic performance and incidence of patientprosthesis mismatch of the complete supraannular Perimount magna bioprosthesis in the aortic position. Thorac Cardiovasc Surg. 2005;53:226-30.

33. Tasca G, Mhagna Z, Perotti S, Centurini PB, Sabatini T, Amaducci A, et al. Impact of prosthesis-patient mismatch on cardiac events and midterm mortality after aortic valve replacement in patients with pure aortic stenosis. Circulation 2006;113:570-6. Erratum in: Circulation. 2006;113:e288.

34. Bleiziffer S, Eichinger WB, Hettich IM, Ruzicka D, Badiu CC, Guenzinger R, et al. Hemodynamic characterization of the Sorin Mitroflow pericardial bioprosthesis at rest and exercise. J Heart Valve Dis. 2009;18:95-100.

35. García-Bengochea J, Sierra J, González-Juanatey JR, Rubio J, Vega M, Fernández AL, et al. Left ventricular mass regression after aortic valve replacement with the new Mitroflow 12A pericardial bioprosthesis. J Heart Valve Dis. 2006; $15: 446-52$ 